\title{
Indirect determination of zeta potential at high ionic strength: Specific application to semipermeable polymeric membranes
}

Bryan D. Coday ${ }^{1}$, Thomas Luxbacher ${ }^{2}$, Amy E. Childress ${ }^{3}$, Nohemi Almaraz ${ }^{1}$, Pei Xu ${ }^{4}$, Tzahi Y. Cath ${ }^{1 *}$

\author{
${ }^{1}$ Colorado School of Mines, Golden, CO, USA \\ ${ }^{2}$ Anton-Paar $\mathrm{GmbH}$, Graz, Austria \\ ${ }^{3}$ University of Southern California, Los Angeles, CA, USA \\ ${ }^{4}$ New Mexico State University, Las Cruces, NM, USA
}

* Corresponding author: 1500 Illinois St., Golden, CO 80401;

Tel.: +1-303-273-3402; fax: +1-303-273-3413

E-mail address: tcath@mines.edu

A manuscript prepared for possible publication in the Journal of Membrane Science

December 2014 


\section{Abstract}

Accurate determination of the electrokinetic properties of semipermeable polymeric membranes is of considerable importance in the development of interfacial models used to interpret membrane fouling and transport phenomena of charged solutes. Of increasing significance is the understanding of membrane charge neutralization and compression of the diffuse layer as described by the electric double layer (EDL) model at environmentally relevant ionic strengths. In this work, the impact of high ionic strengths on membrane zeta potential was investigated using a combination of experimentally determined zeta potential measurements and theoretical modeling. Zeta potential measurements were conducted on asymmetric cellulose triacetate (CTA) and polyamide thin-film composite (TFC) membranes at ionic strengths within the operating limits of an electrokinetic analyzer. Experimental zeta potential results were then

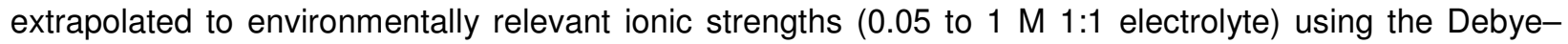
Hückel and Helmholtz-Smoluchowski models. Extrapolated zeta potential results demonstrate that membrane charge neutralization and compression of the diffuse layer are limited to the size of the hydrated counter-ions and full membrane charge neutralization or even charge reversal is not achieved. The expected zeta potential of CTA membranes are similar to that of polyamide TFC membranes at high ionic strength, which has considerable implications in the comparison of membrane performance when treating brackish and saline feed waters. The methodologies developed in this work can help to better understand the contribution of electrostatic forces resulting from zeta potential to the sum of interfacial forces present at the membrane surface.

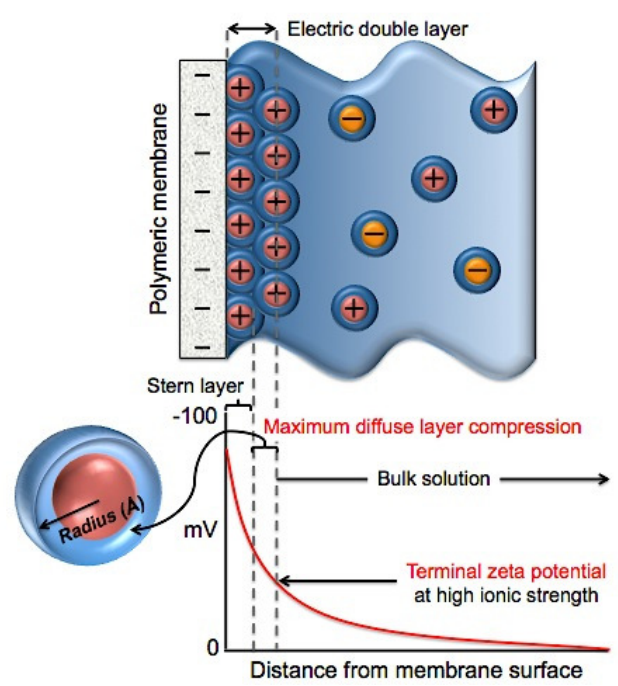

TOC Art

Keywords: streaming potential; zeta potential; forward osmosis; reverse osmosis; nanofiltration; solute rejection 


\section{Introduction}

Membranes are rapidly becoming the leading separation method in a broad range of applications, including treatment of highly impaired waters. This is especially true for semipermeable polymeric nanofiltration (NF), reverse osmosis (RO), and forward osmosis (FO) membranes. NF and RO are pressuredriven membrane processes most commonly employed in brackish water and seawater desalination. They have also been used for treatment of reclaimed water from domestic wastewater in a variety of water reuse scenarios [1, 2] and for applications in the food and beverage industry [3-5]. FO is an osmotically driven membrane process where the driving force for mass transfer is the difference in chemical potential between a concentrated draw solution and a lower salinity feed solution [6-14]. Therefore, FO membranes may be exposed to high ionic strengths on both sides of the membrane, resulting in unique mass transport and contaminant rejection phenomena [15-20]. FO is considered an advanced pretreatment method for downstream pressure-driven membrane processes and has been investigated for treatment of complex feed streams, including anaerobic digester centrate and activated sludge [21-26], landfill leachate [27], hypersaline streams in the mineral recovery industry [28], and exploration and production wastewaters in the oil and gas industry [6, 12, 29, 30].

The fouling propensity of $\mathrm{RO}, \mathrm{NF}$, and FO membranes and mass transport through them are largely dependent on the feed stream characteristics and the complex interactions occurring near the membrane surface. Operating conditions impact the transport mechanisms by which feed stream contaminants (solutes, colloids, and particles) approach the membrane surface and the physicochemical characteristics of the membrane polymer and contaminants govern the interfacial attraction and adhesion forces at the membrane surface. Interfacial attraction and adhesion forces are commonly expressed as the sum of electrostatic, acid-base, van der Waals, and hydrophobic forces between the membrane polymer and feed stream contaminants [31]. Surface charge and hydrophobicity are of particular significance in the development of interfacial force models such as the extended Derjaguin-Landau-VerweyOverbeek (XDLVO) model, which has been used to explain and predict membrane-foulant interactions [31-36]. ENREF 12 ENREF 12 ENREF 12 Electrostatic and hydrophobic interactions are also dominant mechanisms affecting the rejection and transport phenomena of charged and uncharged solutes, respectively, in semipermeable membrane processes [37-45]. ENREF 18

Semipermeable membranes acquire surface charge when in contact with aqueous solutions. This surface charge impacts the spatial distribution and concentration of dissolved solutes at the membranesolution interface, resulting in the formation of an electric double layer (EDL) [46-48]. Surface charge

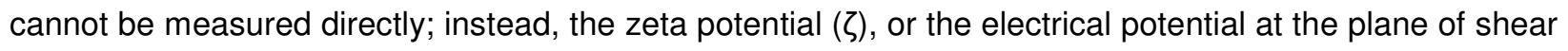
between the stationary and mobile parts of the EDL (the slipping or shear plane) can be determined. The zeta potential of flat membrane surfaces is calculated from streaming potential, which is most commonly measured using an electrokinetic analyzer [49]. The acidity and degree of ionization of the membrane surface, and the $\mathrm{pH}$ and ionic strength of the electrolyte solution influence streaming potential.

Electrokinetic analyzers can measure streaming potential at all $\mathrm{pH}$ values relevant to membrane 
treatment applications; however, determination of streaming potential, and thus the calculation of zeta potential, has been limited to relatively low ionic strength solutions $(<0.1 \mathrm{M})$ [50-52]. The ionic strength at which streaming potential can be reliably measured by commercial electrokinetic analyzers is limited by the sensitivity of their potential measurement devices $(200-500 \mu \mathrm{V})$. When the ionic strength exceeds a certain value, the streaming potential signal assumes values below the acceptable threshold for electrode polarization. The ability to experimentally evaluate the impacts of ionic strength on membrane diffuse layer compression and electrostatic charge shielding using existing electrokinetic analyzers is thus limited to salinities below those of most desalination feed streams and brines.

The Gouy-Chapman-Stern theory and recent modifications have described electrostatic shielding of charged surfaces at increasing ionic strength [53]. These theories predict that counter-ions, most commonly modeled as point charges, aggregate in the Stern layer adjacent to the membrane surface. The concentration of counter-ions in the Stern layer increases with ionic strength until the charged surface is neutralized and the diffuse layer collapses [54]. The ability to estimate membrane zeta potential at increasing ionic strength with these models is limited because ions are hydrated and will exhibit a considerable spatial extension. Therefore, it is likely that the concentration of counter-ions within the Stern layer is limited and complete charge neutralization will not occur. Consequently, XDLVO theory (and similar) assessments of membrane-contaminant interactions using current zeta potential assessment techniques or predictions from the Gouy-Chapman-Stern theory (and similar) may not accurately predict the contribution of electrostatic forces to the sum of interfacial interactions near the membrane surface in current and emerging treatment applications.

The main objective of this study was to develop a comprehensive understanding of electrostatic charge shielding and compression of the diffuse layer as described by the EDL model (and similar). Specifically, the impact of high ionic strength on membrane zeta potential was investigated using a combination of streaming potential measurements and theoretical modeling. A series of streaming potential experiments were conducted on three polymeric membranes at increasing ionic strength (1:1 electrolyte) using an electrokinetic analyzer. Using the Debye-Hückel and Helmholtz-Smoluchowski models, zeta potential results from measurements with electrolyte ionic strength less than $0.05 \mathrm{M}$ were extrapolated to environmentally relevant ionic strengths $(0.05$ to $1 \mathrm{M})$. The methodologies presented in this study provide a more holistic understanding of the interfacial forces near the membrane surface in brackish and saline environments. FO membranes were used in this study due to surging interests in the treatment of hypersaline and complex feed streams using FO; however, the methodology presented is also applicable to other material-water interfaces beyond semipermeable polymeric membranes.

\section{Materials and methods}

\subsection{Membranes}

Three flat sheet FO membranes were investigated. An asymmetric cellulose triacetate (CTA) membrane and a thin-film composite (TFC) polyamide membrane (designated TFC1) were obtained from 
Hydration Technology Innovations (HTI) (Albany, OR). A second TFC polyamide membrane (designated TFC2) was obtained from Oasys Water (Boston, MA).

All membranes were supplied hydrated and were stored in a refrigerator at approximately $5{ }^{\circ} \mathrm{C}$. Prior to all experiments, membrane coupons were thoroughly rinsed and then stored in deionized water at $5{ }^{\circ} \mathrm{C}$ for 24 hours. Rinsed coupons were dried in a desiccator at room temperature for 24 hours prior to characterization.

\subsection{Solution chemistry}

Deionized water (EMD MilliPore, Billerica, MA) and certified ACS-grade potassium chloride (KCl) (Fisher Scientific, Fair Lawn, NJ) were used for preparing the electrolyte solution. For streaming potential measurements, five concentrations $(0.001,0.002,0.01,0.03,0.05 \mathrm{M})$ of $\mathrm{KCl}$ were used, all of which were well below the electrode polarization threshold $(0.1 \mathrm{M})$ of the electrokinetic analyzer used in this study. In one additional set of experiments, lithium chloride $(\mathrm{LiCl})$ and sodium chloride $(\mathrm{NaCl})$ (Fisher Scientific, Fair Lawn, NJ) electrolyte solutions were used at the same molarities as $\mathrm{KCl}$. The goal of employing two additional monovalent solutes was to corroborate the effects of counter-ion hydration radius on membrane charge shielding at high ionic strength.

\subsection{Measurement of membrane zeta potential}

Streaming potential, which can be measured directly or calculated from streaming current and cell resistance measurements using Ohm's law, was measured using a commercial electrokinetic analyzer (SurPASS, Anton-Paar GmbH, Austria). Dried membrane coupons were mounted on a SurPASS adjustable-gap cell that accommodates small planar samples with a rectangular size of $20 \times 10 \mathrm{~mm}$. The cell was mounted on the electrokinetic analyzer and the hydraulic system and gap between the membranes were flushed with deionized water for approximately $2 \mathrm{~min}$. The system was then drained and flushed twice with electrolyte solution to ensure that all deionized water was removed. The electrolyte solution was replaced and recirculated for at least $30 \mathrm{~min}$. This neutralized any localized charge on the $\mathrm{Ag} / \mathrm{AgCl}$ electrodes and minimized variability in streaming potential measurements [39].

All streaming potential measurements were performed at approximately $22{ }^{\circ} \mathrm{C}$ with an average gap height of $116 \pm 2 \mu \mathrm{m}$. At least eight streaming potential measurements (four flowing from left to right and four from right to left) were recorded at each ionic strength and then averaged to calculate the zeta potential. The $\mathrm{pH}$ of the electrolyte solution was not varied during this study. For each membrane type, the same coupon was used for all ionic strengths to minimize experimental error due to changes in membrane physiochemical properties and setup of the adjustable-gap cell. The range of standard deviation observed for all membrane zeta potential measurements was 0.1 to $1.1 \mathrm{mV}$. This range of standard deviation is well below that proposed in a recent study $( \pm 5.0 \mathrm{mV})$ that investigated the propagation of uncertainty from zeta potential measurements for development of an XDLVO model of membrane-colloid interactions [35]. 


\subsection{Extrapolating streaming potential to high ionic strengths}

At ionic strengths exceeding $0.1 \mathrm{M}$ (for a 1:1 electrolyte, and specific for the SurPASS electrokinetic analyzer), the acceptable threshold for electrode polarization is exceeded and streaming potential measurements begin to decay [51]. Because of this, streaming potential measurements above $0.1 \mathrm{M}$ are not valid. To estimate the zeta potential of polymeric FO membranes at higher ionic strengths $(>0.1 \mathrm{M})$, the streaming potential can be determined through extrapolation. To do this, the change in measured streaming potential divided by the change in pressure within the adjustable gap cell (the streaming potential coefficient, $d U_{s t r}(d p)$ can be plotted against the inverse square root of bulk electrolyte conductivity $\left(\mathrm{k}^{-1 / 2}\right)$ on a log-log scale and a linear regression be performed. An example of this linear regression is shown in Fig. 1 for the TFC2 membrane using $\mathrm{KCl}$ electrolyte solution.

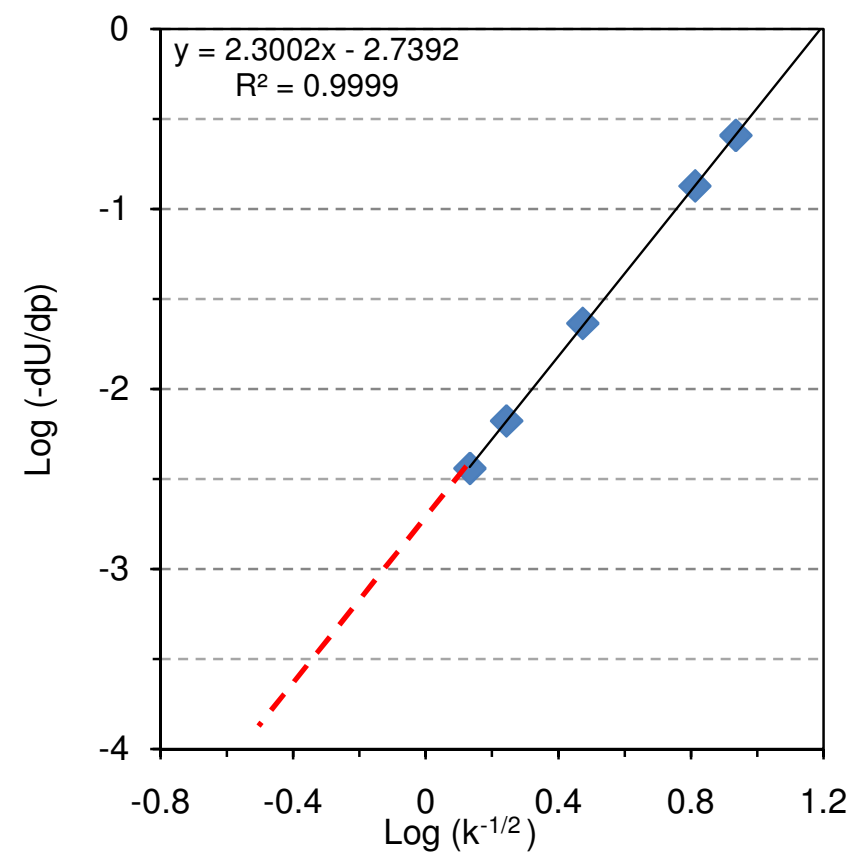

Fig. 1. An example of the relationship between the negative value of the streaming potential coefficient plotted as a function of the inverse square root of bulk electrolyte conductivity (Siemens/meter ${ }^{-1 / 2}$ ) on a log-log scale. This linear relationship can be used to estimate the streaming potential of semipermeable polymeric membranes (red dashed line), and thus their zeta-potential, in high salinity environments using the Helmholtz-Smoluchowski method.

$\mathrm{k}^{-1 / 2}$ was chosen because the inverse square root of the ionic strength is used in estimating the Debye length $\left(\lambda^{-1}\right)$

$$
\lambda^{-1}=\sqrt{\frac{\varepsilon_{r} \varepsilon_{0} k_{B} T}{2 N_{A} e^{2} I}}
$$


where $\varepsilon_{r}$ is the dielectric constant, $\varepsilon_{0}$ is the permittivity of free space, $k_{B}$ is the Boltzmann constant, $T$ is the absolute temperature in Kelvin, $N_{A}$ is the Avogadro number, $e$ is the elementary charge, and $l$ is the ionic strength of the electrolyte. In the measurement and extrapolation range of interest ( $0.05 \mathrm{M}$ to $1 \mathrm{M})$, the conductivity of a 1:1 electrolyte was verified to increase linearly with ionic strength using OLI Stream Analyzer electrolyte simulation software (Cedar Knolls, NJ) (data not shown). Therefore, the substitution of ionic strength with bulk electrolyte conductivity is acceptable. The Debye length is crucial when considering the effects of ionic strength on zeta potential because it determines the extension (or compression) of the diffuse layer and is a critical parameter for describing the spatial distribution and concentration of counter-ions near the membrane surface. The calculation of Debye length can also be used to determine if the hydration radius of the counter-ions impacts the degree of electrostatic charge shielding at high ionic strengths. The dielectric constant of each electrolyte solution at increasing ionic strength was determined from recent work by Levy et al. [55].

Bulk electrolyte conductivity was also chosen for the linear regression because it was used to calculate zeta potential from measured and extrapolated streaming potential using the HelmholtzSmoluchowski equation

$$
\zeta=\frac{d U_{s t r}}{d p} \frac{\eta}{\varepsilon_{r}} \varepsilon_{0}
$$

where $\eta$ is the electrolyte viscosity [39]. This equation is appropriate for investigating electrolyte solutions with ionic strengths greater than $0.001 \mathrm{M}$ [39]. Below $0.001 \mathrm{M}$, the conductivity of the bulk electrolyte solution must be corrected for the contribution of the membrane-liquid interfacial conductance. The derivation of the Helmholtz-Smoluchowski equation used to calculate the zeta potential of semipermeable polymeric membranes has been presented in previous studies and will not be discussed in greater detail $[39,49]$.

\section{Results and discussion}

\subsection{Effects of high salinity on membrane zeta potential}

The zeta potential values for the TFC1, TFC2, and CTA membranes using $\mathrm{KCl}$ electrolyte solutions are shown in Fig. 2 at an average pH of 5.6. Zeta potential values calculated from measured streaming potential data are shown for ionic strengths below $0.05 \mathrm{M} \mathrm{KCl}$ (filled symbols) and calculated from extrapolated streaming potential data is shown for ionic strengths greater than $0.05 \mathrm{M} \mathrm{KCl}$ (empty symbols). The minimum coefficient of determination value $\left(r^{2}\right)$ observed during linear regression was 0.999 throughout the study.

Measured and extrapolated streaming potential values for zeta potential calculation become less negative as ionic strength increases until $0.2 \mathrm{M} \mathrm{KCl}$; this phenomena is predicted by the Gouy-ChapmanStern theory. Although this theory is simplified and based on ideal boundary conditions, it explains the suppression of electrokinetic phenomena due to the gradual compression of the diffuse layer as ionic strength increases. 

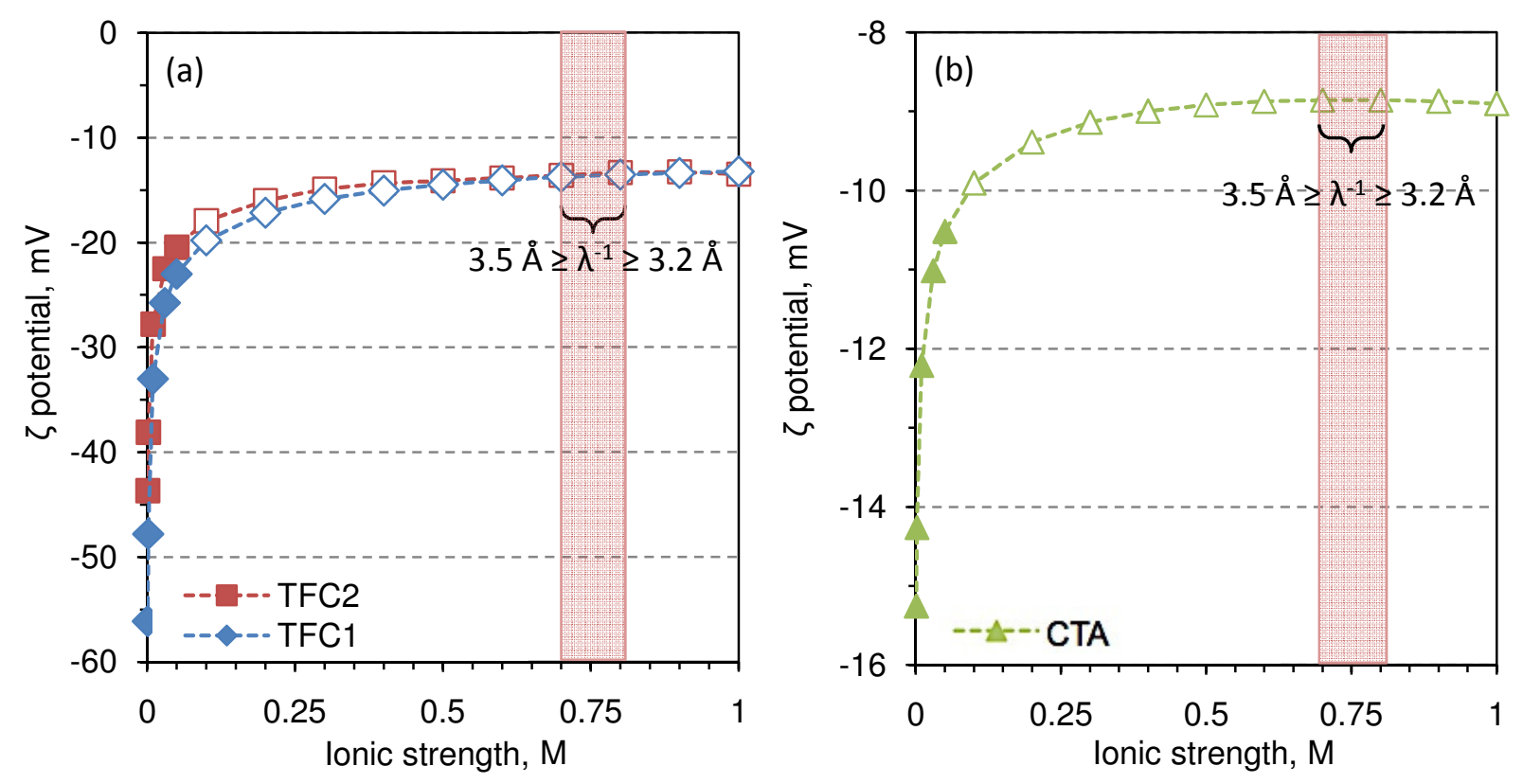

Fig. 2. Values of zeta potential calculated from measured and extrapolated streaming potential for (a) the TFC1, TFC2, and (b) CTA membrane as a function of electrolyte ionic strength. All experiments were conducted in the presence of increasing concentrations of $\mathrm{KCl}$ electrolyte in deionized water (average $\mathrm{pH}$ of 5.6). Values above $0.05 \mathrm{M}$ are extrapolated from measured streaming potential. To better show the values of zeta potential calculated from measured streaming potential as a function of electrolyte ionic strength, a graph with ionic strength presented on a log scale is shown in Fig. A in the Appendix.

At ionic strengths greater than approximately $0.2 \mathrm{M} \mathrm{KCl}$, changes in zeta potential become diminishingly small. In fact, zeta potential values extrapolated to $1 \mathrm{M} \mathrm{KCl}$ were only slightly less negative than those observed near $0.2 \mathrm{M} \mathrm{KCl}$. It can be seen that the zeta potential remains essentially constant at some ionic strength greater than $0.7 \mathrm{M}$ to $0.8 \mathrm{M} \mathrm{KCl}$ for all three membranes. In this range of ionic strengths $(0.7 \mathrm{M}$ to $0.8 \mathrm{M} \mathrm{KCl})$, the Debye length (Eq. 1) is calculated to range from $3.5 \AA$ to $3.2 \AA$, which is in close agreement with the hydration radius of potassium (3.31 Ä) [56-59]. The extent of diffuse layer compression of each membrane is thus limited to the size of the hydrated counter-ions [60,61] and it is unlikely that the zeta potential of polymeric membranes will fall to $0 \mathrm{mV}$ when electrostatically shielded with indifferent monovalent counter-ions. These findings go against the Gouy-Chapman-Stern theory and recent modifications because the counter-ions aggregated in the Stern layer adjacent to the membrane surface are commonly modeled as point charges when in fact they are hydrated and exhibit a considerable spatial extension [53]. The conclusions drawn from this extrapolation method are in agreement with data obtained using a non-commercial (custom-built) electrokinetic analyzer [60, 61], electroacoustic measurements [54,62, 63], and yield stress measurements [64].

It is also shown in Fig. 2 that the impact of increasing ionic strength on membrane zeta potential can vary depending on the polymeric chemistry of the semipermeable membrane. While both TFC membranes (Fig. 2a) exhibited a very negative zeta potential at low ionic strength $(0.001 \mathrm{M} \mathrm{KCl})$, the zeta po- 
tential of TFC1 $(-56 \mathrm{mV})$ is noticeably more negative than that of TFC2 $(-43 \mathrm{mV})$. It is well documented that the surface functional groups of polyamide TFC membranes are ionizable and that the streaming potential values of these membrane are dependent on the density of surface functional groups and electrolyte $\mathrm{pH}[35,39,49,51,65]$. Although the absolute density of surface functional groups for TFC1 and TFC2 were not quantified in this study, results in Fig. 2 show that the TFC1 membrane likely has a higher density of surface functional groups than the TFC2 membrane at $\mathrm{pH}$ 5.6. At increasingly higher ionic strengths, the polymeric surfaces of both membranes demonstrated a comparable affinity for electrostatic charge shielding by hydrated potassium counter-ions and a similar, terminal zeta potential value $(-14$ $\mathrm{mV}$ ). This preferential approach and electrostatic charge shielding of polyamide TFC membranes by the hydrated potassium cation is in agreement with the transport phenomena observed in a recent benchscale evaluation of the same FO membranes [16]. The rate of bi-directional cation diffusion through the polyamide TFC membranes drastically exceeded that of anions and increased with membrane hydrophilicity. The similar affinity for electrostatic charge shielding and terminal zeta potential value for TFC1 and TFC2, despite different zeta potential values at low ionic strength, suggests that charge shielding at increasing counter-ion concentrations might also depend on other physiochemical properties of the membrane surface. Ongoing research is focusing on the influence of membrane hydrophilicity and surface morphology on electrostatic charge shielding by hydrated counter-ions and the resulting impacts on the terminal zeta potential value.

Unlike the TFC membranes, the CTA membrane is not ionizable and its negative zeta potential (Fig. 2b) has been commonly explained by the accumulation of hydroxide ions at the membrane surface [66]; yet, there is still a dispute in the literature about the origin of these hydroxide ions [67]. It is shown in Fig. 2 that significantly less negative zeta potential values were calculated for the CTA membrane than the TFC membranes. In general, CTA membranes are cellulose-based with acetyl and hydroxyl functional groups [49] that are non-ionogenic [46]. Therefore, it is likely that charge shielding was largely attributed to the co-adsorption of hydroxide and chloride ions in the Stern layer at the membrane-liquid interface [49]. While the hydration radius and number of hydrating water molecules are similar for chloride (3.32 $\AA$ ) and potassium (3.31 $\AA$ ), the dissolution of chloride results in a much smaller perturbation to the surrounding water structure than does potassium [56]. When dissolved in water, single hydrogen atoms from nearby water molecules are pointed towards the chloride ion, leaving the remaining hydrogen atoms and electron pairs available for bonding to other water molecules or ions. For potassium, the oxygen atoms from nearby water molecules are oriented inwards towards the cation, which results in unstable hydrogen bonding and a significant disruption to the nearby network of water molecules [56]. Consequently, chloride might preferentially aggregate in the CTA Stern layer at all ionic strengths due to its greater spatial order and potassium would remain in the diffuse layer where it could contribute to electrostatic charge shielding. This theory is in agreement with the transport phenomena observed in a recent publication, where anions preferentially diffused through CTA [16]. Therefore, the electrostatic charge neutralization of membranes exhibiting negligible surface ionization, especially CTA membranes, may largely depend on 
the hydrated structure and characteristics of the ions in solution (e.g., perturbation of nearby water matrix) and be less dependent on the hydrophilicity or surface morphology of the membrane.

It must be noted that a significant challenge in measuring zeta potential for porous materials, such as polymeric membranes, is the possible influence of the porous structure on the measured streaming potential. Yaroshchuk and Ribitsch [68] first indicated the effect of "channel wall" conductance on zeta potential when calculated from streaming potential measurements. Almost ten years later, Yaroshchuk and Luxbacher [69] further investigated the effects of material porosity on streaming current measurements and the zeta potential derived thereof. While the effect of streaming current inside pores is significant or even dominant for microfiltration and ultrafiltration membranes, the overestimation of zeta potential or deterioration of reliable streaming current results are not expected when investigating $\mathrm{NF}$, $\mathrm{RO}$, and FO membranes due to the dense active layer that lacks surface pores. Deon et al. [70] recently presented streaming current results, which suggested an enormous influence of the porous support layer of TFC NF membranes on the measured streaming potential. However, the interpretation of their results may have been misled by their experimental setup, which did not provide the conditions required for a fully developed flow pattern inside the streaming channel [71]. In the current study, comparison of the zeta potential results for each membrane (CTA, TFC1, and TFC2) calculated from streaming potential $\left(U_{s t r}\right)$ with streaming current $\left(I_{\text {str }}\right)$ measurements at ionic strengths ranging from $0.001 \mathrm{M}$ to $0.05 \mathrm{M}$ showed no evidence for any contribution of the porous support layer. In fact, the two sets of zeta potential data are almost the same, with an average experimental error of $3.7 \pm 1.5 \%$ throughout the study (e.g., $\zeta\left(I_{s t r}\right)=-37.7 \pm 1.0$ $\mathrm{mV}$ and $\zeta\left(U_{s t r}\right)=-35.7 \pm 0.2 \mathrm{mV}$ at $0.002 \mathrm{M} \mathrm{KCl}$ for membrane TFC2 (Fig. B in the Appendix).

\subsection{Effects of counter ion hydration radius on membrane zeta potential}

The effect of counter-ion hydration radius on membrane zeta potential at high ionic strengths was validated in an additional set of measurements and extrapolations (Fig. 3). By comparing the effect of increasing ionic strength of $\mathrm{KCl}, \mathrm{NaCl}$, and $\mathrm{LiCl}$ on the TFC2 membrane zeta potential, it is clearly shown that electrostatic charge shielding by the hydrated counter-ion decreases proportionally with decreasing electrolyte conductivity $(\mathrm{K}>\mathrm{Na}>\mathrm{Li})$. Additionally, as the hydration radius of the counter-ion increased $(\mathrm{Li}>\mathrm{Na}>\mathrm{K})$, the terminal zeta potential value became more negative and the ionic strength at which no further change in zeta potential occurred decreased. In other words, the terminal zeta potential value observed for potassium, sodium, and lithium counter-ions was $-14 \mathrm{mV},-18 \mathrm{mV}$, and $-22 \mathrm{mV}$, respectively. For $\mathrm{KCl}$ the ionic strength at which no further changes in zeta potential were observed was between 0.7 $\mathrm{M}$ and $0.8 \mathrm{M} \mathrm{KCl}$, corresponding to a Debye length between $3.5 \AA$ and $3.2 \AA$. For $\mathrm{NaCl}$ the ionic strength at which no further changes in zeta potential were observed was between $0.6 \mathrm{M}$ and $0.7 \mathrm{M} \mathrm{NaCl}$, corresponding to a Debye length between $3.7 \AA$ and $3.4 \AA$. For $\mathrm{LiCl}$ the ionic strength at which no further changes in zeta potential were observed was between $0.5 \mathrm{M}$ and $0.6 \mathrm{M} \mathrm{LiCl}$, corresponding to a Debye length between $4.1 \AA$ and $3.7 \AA$. These values are in close agreement with the hydration radii of the potassium (3.31 $\AA$ ), sodium (3.58 $\AA$ ), and lithium (3.82 $\AA$ ) counter-ions, which clearly demonstrates that the 
extent of diffuse layer compression of each membrane is limited to the size of the hydrated counter-ion. These findings are in close agreement with Vinogradov et al. [60], who experimentally investigated streaming potential coefficients in sandstones saturated with $\mathrm{KCl}$ and $\mathrm{NaCl}$ brines. These results also validate our conclusion that the zeta potential of polymeric membranes are unlikely to fall to $0 \mathrm{mV}$ when electrostatically shielded with a variety of indifferent monovalent counter-ions.

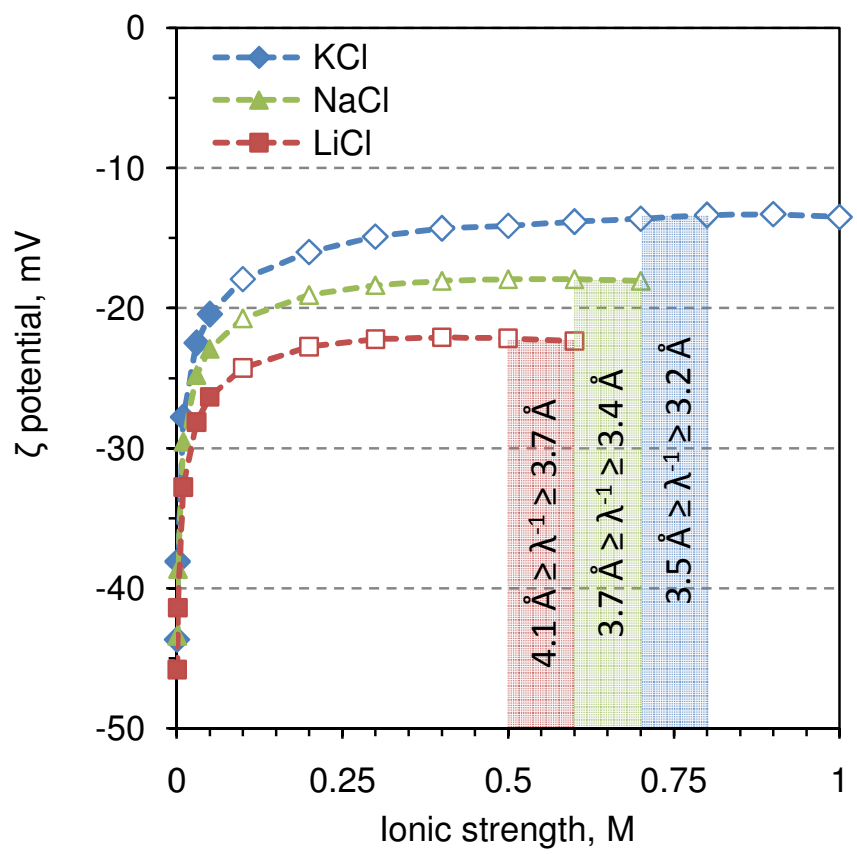

Fig. 3. Values of zeta potential calculated from measured and extrapolated streaming potential for the TFC2 membrane as a function of electrolyte ionic strength. Measurements were conducted in the presence of increasing concentrations of $\mathrm{KCl}, \mathrm{NaCl}$, and $\mathrm{LiCl}$ solutions in deionized water (average $\mathrm{pH} \mathrm{5.6).}$ Values above $0.05 \mathrm{M}$ are calculated from extrapolated streaming potential measurements. To better show the values of zeta potential calculated from measured streaming potential as a function of electrolyte ionic strength, a graph with ionic strength presented on a log scale is shown in Fig. $C$ in the Appendix.

The effect of cation hydration radius on the zeta potential of the TFC2 membrane correlates well with recent membrane performance tests conducted on the same membrane [16]. Fig. 4a shows the rejection of a variety of cations and anions $\left(\mathrm{MgSO}_{4}, \mathrm{LiBr}\right.$, and $\left.\mathrm{KNO}_{3}\right)$ by the TFC2 membrane when operated in FO mode (active layer facing the feed solution); the feed solution contained $20 \mathrm{mM}$ of each of the three salts. When using $\mathrm{NaCl}$ draw solution $(1 \mathrm{M})$, the reverse diffusion $[15,17,72]$ of sodium ions across the membrane into the feed solution (Fig. $4 \mathrm{~b}$ ) exceeded that of the chloride ions by nearly $50 \%$; this phenomena was attributed to the preferential approach of cations towards the negatively charged polyamide active layer. To maintain solution electroneutrality, the rejection of cations in the feed solution was significantly less than that of anions (Fig. 4a). This data also shows that the order of rejection of feed stream cations correlated well with monovalent cation hydration radius $(\mathrm{Li}>\mathrm{K})$. It should be noted that rejection of magnesium cations was highest, which exhibit greater hydration radii than lithium and potassium; however, polyvalent ions can interact specifically with the membrane surface (i.e., adsorption to the membrane 
surface) [39]. Therefore, the influence of hydration radius on the rejection of polyvalent ions and on charge shielding is not clear and is currently under investigation. Similar conclusions were drawn for an additional TFC membrane tested in that study. This correlation between monovalent hydration radius and ion rejection is in close agreement with the effect of cation hydration radius on membrane zeta potential and the finite compression of the diffuse layer shown in Fig. 3 . It is evident that, even in feed streams containing numerous counter-ions, the preferential approach of counter-ions towards the membrane surface and their subsequent diffusion through the membrane active layer strongly correlates with the size of the hydrated radius of the solute.
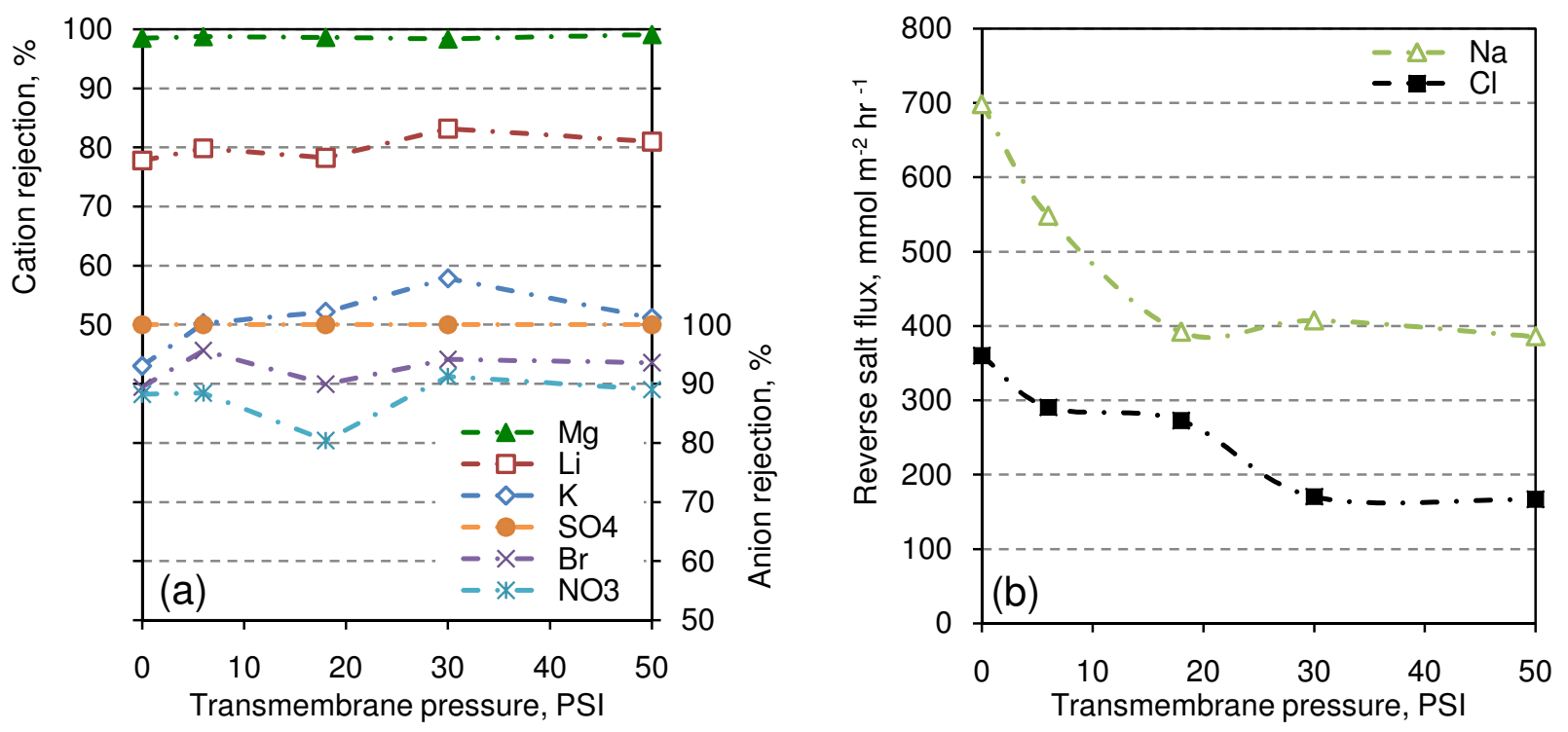

Fig. 4. The performance of TFC2 was evaluated in a recent study that investigated the (a) ion rejection and (b) reverse salt flux of sodium and chloride as a function of transmembrane pressure. Experiments were conducted using $1 \mathrm{M} \mathrm{NaCl}$ draw solution and inorganic feed solution $\left(\mathrm{MgSO}_{4}, \mathrm{LiBr}\right.$, and $\left.\mathrm{KNO}_{3}\right)$ at $20 \pm 0.5{ }^{\circ} \mathrm{C}$. The concentration of each salt in the feed solution was $20 \mathrm{mM}$. The color and symbol for $\mathrm{Li}, \mathrm{K}$, and $\mathrm{Na}$ match those used in Fig. 3. Adapted from [16].

\subsection{Conclusions}

lonic strength has considerable impacts on membrane zeta potential. Electrostatic charge shielding and compression of the diffuse layer due to increasing ionic strength reduces the negative zeta potential of semipermeable polymeric membranes, thus diminishing the contribution of electrostatic forces to the sum of interfacial interactions at the membrane-liquid interface. The membrane zeta potential is larger in magnitude when measured in dilute electrolyte solutions, thus over-predicting the effect of electrostatic forces and providing unrealistic information when comparing the electrostatic forces of different polymeric membranes at environmentally relevant ionic strengths. These results also jeopardize the commonly accepted assumption that the overall membrane surface charge is neutralized or reversed at high ionic strengths. 
Accurately estimating membrane zeta potential is critical when interpreting membrane fouling propensity and the transport phenomena of charged contaminants in the presence of brackish and saline feed streams. In semipermeable membrane processes, results from this study are especially important for understanding the electrostatic interactions at the feed solution-membrane interface. In FO specifically, these results may help to explain preferential bi-directional solute flux of anions and cations across current and emerging membranes and guide the selection of draw solutions to help mitigate the effects of reverse solute flux on cake enhanced concentration polarization [15, 17, 73]. Zeta potential values calculated from experimental data and extrapolations can thus provide more realistic estimations of membrane zeta potential and a method for comparing electrostatic properties of different polymer chemistries beyond the experimental limitations of electrokinetic analyzers.

\section{Acknowledgments}

Support of this investigation was provided by DOE/RPSEA project 10122-39 and WateReuse Colorado. The authors would like to thank Hydration Technology Innovations and Oasys Water for providing membranes for the study and to Anton-Paar for providing technical support. The authors would also like to thank Ryan Holloway for his technical insight on solute transport and membrane-foulant interactions in membrane processes.

\section{References}

[1] C. Bellona, J.E. Drewes, Viability of a low-pressure nanofilter in treating recycled water for water reuse applications: A pilot-scale study, Water Research 41 (2007) 3948-3958.

[2] C. Bellona, D. Heil, C. Yu, P. Fu, J.E. Drewes, The pros and cons of using nanofiltration in lieu of reverse osmosis for indirect potable reuse applications, Separation and Purification Technology 85 (2012) 69-76.

[3] F. Salehi, Current and future applications for nanofiltration technology in the food processing, Food and Bioproducts Processing 92 (2013) 161-177.

[4] A. Román, J. Wang, J. Csanádi, C. Hodúr, G. Vatai, Experimental investigation of the sweet whey concentration by nanofiltration, Food and Bioprocess Technology 4 (2011) 702-709.

[5] C. Bellona, Nanofiltration-Theory and Application, Desalination: Water from Water (2014) 205253.

[6] B.D. Coday, P. Xu, E.G. Beaudry, J. Herron, K. Lampi, N.T. Hancock, T.Y. Cath, The sweet spot of forward osmosis: Treatment of produced water, drilling wastewater, and other complex and difficult liquid streams, Desalination 333 (2014) 23-35.

[7] T.Y. Cath, A.E. Childress, M. Elimelech, Forward osmosis: Principles, applications, and recent developments, Journal of membrane science 281 (2006) 70-87.

[8] S. Zhao, L. Zou, C.Y. Tang, D. Mulcahy, Recent developments in forward osmosis: Opportunities and challenges, Journal of Membrane Science 396 (2012) 1-21. 
[9] L. Chekli, S. Phuntsho, H.K. Shon, S. Vigneswaran, J. Kandasamy, A. Chanan, A review of draw solutes in forward osmosis process and their use in modern applications, Desalination and Water Treatment 43 (2012) 167-184.

[10] T.-S. Chung, S. Zhang, K.Y. Wang, J. Su, M.M. Ling, Forward osmosis processes: Yesterday, today and tomorrow, Desalination 287 (2012) 78-81.

[11] J.-J. Qin, W.C.L. Lay, K.A. Kekre, Recent developments and future challenges of forward osmosis for desalination: A review, Desalination and Water Treatment 39 (2012) 123-136.

[12] D.L. Shaffer, J.R. Werber, H. Jaramillo, S. Lin, M. Elimelech, Forward osmosis: Where are we now?, Desalination (2014) doi:10.1016/j.desal.2014.1010.1031.

[13] C. Klaysom, T.Y. Cath, T. Depuydt, I.F.J. Vankelecom, Forward and pressure retarded osmosis: Potential solutions for global challenges in energy and water supply, Chemical Society Reviews 42 (2013) 6959-6989.

[14] T.Y. Cath, Osmotically and thermally driven membrane processes for enhancement of water recovery in desalination processes, Desalination and Water Treatment 15 (2010) 279-286.

[15] N.T. Hancock, W.A. Phillip, M. Elimelech, T.Y. Cath, Bidirectional permeation of electrolytes in osmotically driven membrane processes, Environmental Science \& Technology 45 (2011) 1064210651.

[16] B.D. Coday, D.M. Heil, P. Xu, T.Y. Cath, Effects of transmembrane hydraulic pressure on performance of forward osmosis membranes, Environmental Science \& Technology 47 (2013) 2386-2393.

[17] N.T. Hancock, T.Y. Cath, Solute coupled diffusion in osmotically driven membrane processes, Environmental Science \& Technology 43 (2009) 6769-6775.

[18] B.D. Coday, B.G. Yaffe, P. Xu, T.Y. Cath, Rejection of trace organic compounds by forward osmosis membranes: A literature review, Environmental science \& technology 48 (2014) 36123624.

[19] A. Achilli, T.Y. Cath, A.E. Childress, Selection of inorganic-based draw solutions for forward osmosis applications, Journal of Membrane Science 364 (2010) 233-241.

[20] R.W. Holloway, J. Regnery, L.D. Nghiem, T.Y. Cath, Removal of trace organic chemicals and performance of a novel hybrid ultrafiltration-osmotic membrane bioreactor, Environmental science \& technology 48 (2014) 10859-10868.

[21] R.W. Holloway, A.E. Childress, K.E. Dennett, T.Y. Cath, Forward osmosis for concentration of anaerobic digester centrate, Water Research 41 (2007) 4005-4014.

[22] R.W. Holloway, A.S. Wait, A.F. da Silva, J. Herron, M.D. Schutter, K. Lampi, T.Y. Cath, Longterm pilot scale investigation of novel hybrid ultrafiltration-osmotic membrane bioreactors, Desalination (2014) doi:10.1016/j.desal.2014.1005.1040.

[23] A. Achilli, T.Y. Cath, E.A. Marchand, A.E. Childress, The forward osmosis membrane bioreactor: a low fouling alternative to MBR processes, Desalination 239 (2009) 10-21.

[24] E. Cornelissen, D. Harmsen, E. Beerendonk, J. Qin, H. Oo, K. De Korte, J. Kappelhof, The innovative osmotic membrane bioreactor (OMBR) for reuse of wastewater, Water Science \& Technology 63 (2011) 1557-1565. 
[25] A. Alturki, J. McDonald, S.J. Khan, F.I. Hai, W.E. Price, L.D. Nghiem, Performance of a novel osmotic membrane bioreactor (OMBR) system: flux stability and removal of trace organics, Bioresource technology 113 (2012) 201-206.

[26] D. Xiao, C.Y. Tang, J. Zhang, W.C. Lay, R. Wang, A.G. Fane, Modeling salt accumulation in osmotic membrane bioreactors: implications for FO membrane selection and system operation, Journal of Membrane Science 366 (2011) 314-324.

[27] R. York, R. Thiel, E. Beaudry, Full-scale experience of direct osmosis concentration applied to leachate management, 7th International Waste Management and Landfill Symposium (Sardinia'99), Cagliari, Italy,

[28] T.Y. Cath, K.L. Hickenbottom, B.D. Coday, A.R. Furtado, Forward osmosis and membrane distillation application for sustainable recovery of water and minerals from hypersaline brines, AMTA/AWWA 2013 Membrane Technology Conference, San Antonio, TX, February 25-28.

[29] K.L. Hickenbottom, N.T. Hancock, N.R. Hutchings, E.W. Appleton, E.G. Beaudry, P. Xu, T.Y. Cath, Forward osmosis treatment of drilling mud and fracturing wastewater from oil and gas operations, Desalination 312 (2013) 60-66.

[30] D.L. Shaffer, L.H. Arias Chavez, M. Ben-Sasson, S. Romero-Vargas Castrillón, N.Y. Yip, M. Elimelech, Desalination and reuse of high-salinity shale gas produced water: drivers, technologies, and future directions, Environmental Science \& Technology 47 (2013) 9569-9583.

[31] J.A. Brant, A.E. Childress, Colloidal adhesion to hydrophilic membrane surfaces, Journal of Membrane Science 241 (2004) 235-248.

[32] P. Bacchin, P. Aimar, V. Sanchez, Model for colloidal fouling of membranes, AIChE journal 41 (1995) 368-376.

[33] E. Verwey, Theory of the stability of lyophobic colloids, Journal of Physical Chemistry 51 (1947) 631-636.

[34] E.M. Vrijenhoek, S. Hong, M. Elimelech, Influence of membrane surface properties on initial rate of colloidal fouling of reverse osmosis and nanofiltration membranes, Journal of Membrane Science 188 (2001) 115-128.

[35] S. Muthu, A. Childress, J. Brant, Propagation-of-uncertainty from contact angle and streaming potential measurements to XDLVO model assessments of membrane-colloid interactions, Journal of Colloid and Interface Science 428 (2014) 191-198.

[36] M.M. Motsa, B.B. Mamba, A. D'Haese, E.M.V. Hoek, A.R.D. Verliefde, Organic fouling in forward osmosis membranes: The role of feed solution chemistry and membrane structural properties, Journal of Membrane Science 460 (2014) 99-109.

[37] M. Xie, L.D. Nghiem, W.E. Price, M. Elimelech, Relating rejection of trace organic contaminants to membrane properties in forward osmosis: Measurements, modelling and implications, Water Research 49 (2014) 265-274.

[38] A.E. Childress, M. Elimelech, Relating Nanofiltration Membrane Performance to Membrane Charge (Electrokinetic) Characteristics, Environmental Science \& Technology 34 (2000) 37103716.

[39] A.E. Childress, M. Elimelech, Effect of solution chemistry on the surface charge of polymeric reverse osmosis and nanofiltration membranes, Journal of Membrane Science 119 (1996) 253268. 
[40] S. Bandini, J. Drei, D. Vezzani, The role of $\mathrm{pH}$ and concentration on the ion rejection in polyamide nanofiltration membranes, Journal of Membrane Science 264 (2005) 65-74.

[41] C. Bellona, J.E. Drewes, The role of membrane surface charge and solute physico-chemical properties in the rejection of organic acids by NF membranes, Journal of Membrane Science 249 (2005) 227-234.

[42] S. Déon, A. Escoda, P. Fievet, R. Salut, Prediction of single salt rejection by NF membranes: An experimental methodology to assess physical parameters from membrane and streaming potentials, Desalination 315 (2013) 37-45.

[43] G. Hagmeyer, R. Gimbel, Modelling the rejection of nanofiltration membranes using zeta potential measurements, Separation and Purification Technology 15 (1999) 19-30.

[44] T. Hoang, G. Stevens, S. Kentish, The effect of feed $\mathrm{pH}$ on the performance of a reverse osmosis membrane, Desalination 261 (2010) 99-103.

[45] M.H. Oo, S.L. Ong, Implication of zeta potential at different salinities on boron removal by RO membranes, Journal of Membrane Science 352 (2010) 1-6.

[46] P. Brezonik, W. Arnold, Water chemistry: an introduction to the chemistry of natural and engineered aquatic systems, Oxford University Press, 2011, 019981354X.

[47] R.J. Hunter, Zeta potential in colloid science: principles and applications, Academic press London, 1981, 9780123619617.

[48] S. McLaughlin, The electrostatic properties of membranes, Annual Review of Biophysics and Biophysical Chemistry 18 (1989) 113-136.

[49] M. Elimelech, W.H. Chen, J.J. Waypa, Measuring the zeta (electrokinetic) potential of reverse osmosis membranes by a streaming potential analyzer, Desalination 95 (1994) 269-286.

[50] J.H. Masliyah, S. Bhattacharjee, Frontmatter, in: Electrokinetic and Colloid Transport Phenomena, John Wiley \& Sons, Inc., 2005, 978-0-471-78882-9.

[51] G. Hurwitz, G.R. Guillen, E.M.V. Hoek, Probing polyamide membrane surface charge, zeta potential, wettability, and hydrophilicity with contact angle measurements, Journal of Membrane Science 349 (2010) 349-357.

[52] K.J. Kim, A.G. Fane, M. Nystrom, A. Pihlajamaki, W.R. Bowen, H. Mukhtar, Evaluation of electroosmosis and streaming potential for measurement of electric charges of polymeric membranes, Journal of Membrane Science 116 (1996) 149-159.

[53] J. Lyklema, Fundamentals of Interface and Colloid Science: Solid-Liquid Interfaces, Academic Press, London, 1995, 978-0124605244.

[54] A. Dukhin, S. Dukhin, P. Goetz, Electrokinetics at high ionic strength and hypothesis of the double layer with zero surface charge, Langmuir 21 (2005) 9990-9997.

[55] A. Levy, D. Andelman, H. Orland, Dielectric constant of ionic solutions: A field-theory approach, Physical review letters 108 (2012) 227801.

[56] R. Mancinelli, A. Botti, F. Bruni, M.A. Ricci, A.K. Soper, Hydration of Sodium, Potassium, and Chloride lons in Solution and the Concept of Structure Maker/Breaker, Journal of Physical Chemistry B 111 (2007) 13570-13577. 
[57] J. Mähler, I. Persson, A study of the hydration of the alkali metal ions in aqueous solution, Inorganic Chemistry 51 (2011) 425-438.

[58] A. Volkov, S. Paula, D. Deamer, Two mechanisms of permeation of small neutral molecules and hydrated ions across phospholipid bilayers, Bioelectrochemistry and Bioenergetics 42 (1997) 153-160.

[59] B.E. Conway, B. Conway, Ionic hydration in chemistry and biophysics, Elsevier Amsterdam, $1981,978-0444419477$.

[60] J. Vinogradov, M. Jaafar, M. Jackson, Measurement of streaming potential coupling coefficient in sandstones saturated with natural and artificial brines at high salinity, Journal of Geophysical Research: Solid Earth (1978-2012) 115 (2010)

[61] M. Jaafar, J. Vinogradov, M. Jackson, Measurement of streaming potential coupling coefficient in sandstones saturated with high salinity $\mathrm{NaCl}$ brine, Geophysical Research Letters 36 (2009)

[62] S.B. Johnson, P.J. Scales, T.W. Healy, The Binding of Monovalent Electrolyte lons on a-Alumina. I. Electroacoustic Studies at High Electrolyte Concentrations, Langmuir 15 (1999) 2836-2843.

[63] R. Greenwood, Review of the measurement of zeta potentials in concentrated aqueous suspensions using electroacoustics, Advances in Colloid and Interface Science 106 (2003) 55-81.

[64] S.B. Johnson, G.V. Franks, P.J. Scales, T.W. Healy, The Binding of Monovalent Electrolyte lons on a-Alumina. II. The Shear Yield Stress of Concentrated Suspensions, Langmuir 15 (1999) 2844-2853.

[65] S.L. Walker, S. Bhattacharjee, E.M. Hoek, M. Elimelech, A novel asymmetric clamping cell for measuring streaming potential of flat surfaces, Langmuir 18 (2002) 2193-2198.

[66] R. Zimmermann, U. Freudenberg, R. Schweiß, D. Küttner, C. Werner, Hydroxide and hydronium ion adsorption - A survey, Current Opinion in Colloid \& Interface Science 15 (2010) 196-202.

[67] J.K. Beattie, A.M. Djerdjev, G.G. Warr, The surface of neat water is basic, Faraday Discussions 141 (2009) 31-39.

[68] A. Yaroshchuk, V. Ribitsch, Role of channel wall conductance in the determination of $\zeta$-potential from electrokinetic measurements, Langmuir 18 (2002) 2036-2038.

[69] A. Yaroshchuk, T. Luxbacher, Interpretation of electrokinetic measurements with porous films: Role of electric conductance and streaming current within porous structure, Langmuir 26 (2010) 10882-10889.

[70] S. Déon, P. Fievet, C. Osman Doubad, Tangential streaming potential/current measurements for the characterization of composite membranes, Journal of Membrane Science 423 (2012) 413421.

[71] A. Yaroshchuk, E.E.L. Bernal, T. Luxbacher, Electrokinetics in undeveloped flows, Journal of colloid and interface science 410 (2013) 195-201.

[72] W.A. Phillip, J.S. Yong, M. Elimelech, Reverse draw solute permeation in forward osmosis: modeling and experiments, Environmental science \& technology 44 (2010) 5170-5176.

[73] E.M. Hoek, M. Elimelech, Cake-enhanced concentration polarization: a new fouling mechanism for salt-rejecting membranes, Environmental Science \& Technology 37 (2003) 5581-5588. 